ORIGINAL ARTICLE

\title{
Prevalence of Hair Loss among Men and its Association with Smoking and Stress: A Case Study in the City of Lahore, Pakistan
}

\author{
${ }^{1}$ M.Phil Scholar Public Health, University of the Punjab \\ ${ }^{2}$ Assistant Professor, University of the Punjab \\ ${ }^{3}$ Assistant Professor Community Medicine \& Public Health /Gulab Devi Educational Complex, Lahore \\ ${ }^{4}$ Lecturer, University of Jhang \\ ${ }^{5}$ Assistant Professor, ISCS, University of the Punjab \\ ${ }^{6}$ National Institute of Food and Technology, University of Agriculture \\ Correspondence: Dr. Javeria Saleem, Email: javeria.hasan@hotmail.com, Cell: +92-3004366011
}

RAJA ZUBAIR ABBAS ${ }^{1}$, JAVERIA SALEEM ${ }^{2}$, USMAN JAVED IQBAL $^{3}$, ZOYA SAQLAIN $^{4}$, MUHAMMAD ISHAQ $^{5}$, ALI RAZA $^{6}$

\begin{abstract}
Aim: To explore the prevalence of hair loss and its relation to men's stress and smoking,

Methodology: A cross sectional study attempts to explore the prevalence of baldness among the male residents of Lahore. For this purpose, a randomized sample of the male population was taken into consideration. The sociodemographic details, along with the smoking status of the sample were determined. Moreover, the body mass index (BMI) was also determined by referring to a prefixed formula. Baldness and stress levels were also quantified by taking into account the Norwood Hamilton categorical scale, and the perceived stress scale, respectively. A total of 250 male members were invited to participate in the research.

Results: The study results showed that $51.2 \%, 41.2 \%$ and $7.6 \%$ of male experienced moderate, high and low level of stress respectively. When taking the Norwood Hamilton categorical scale into account, the results revealed that most prevalent type of baldness was Type II, which is the fronto-temporal hairline recession, with $19.2 \%$ of the individuals experiencing it. Age was significantly associated with baldness. Similarly a higher frequency of baldness was recorded in those men who lived in a nuclear family arrangement.

Conclusion: No association was found between the type of baldness, stress level and smoking status.

Keyword: Alopecia, Baldness, Norwood Hamilton categorical scale, Perceived stress scale, smoking
\end{abstract}

\section{INTRODUCTION}

On average, humans lose 50 to 100 hairs per day. ${ }^{1}$ This usually doesn't cause noticeable hair loss because new hairs start growing at the same time, as it is well proven that the fastest growing tissue in the human body is the hair follicle. ${ }^{2}$ However, a daily hair fall that exceeds the said limit, is then labelled as "balding". ${ }^{3}$ The incidence of hair loss is increasing globally and both men and women are equally affected by a hair loss, ${ }^{4}$ that is related to several factors such as family trajectories, aging, hormonal changes, telogen effluvium (hair shedding due to illness), etc. ${ }^{5}$ The psychological disequilibrium has been on the rise amongst the young male members of the society, who directly associate their physical appearance with feelings of low self esteem or insecurity, due to the hair loss that they have experienced. ${ }^{6}$ Interestingly, stress or psychological distress is also considered to be one of the most significant factors that lead to baldness in both males and females, which eventually causes loss of sleep and appetite, previous empirical literature found this association. ${ }^{7,8}$

Along with psychological disequilibrium, tobacco consumption or smoking is a considerable determinant of baldness in males. ${ }^{5}, 9,10$ Some studies have found a significant relationship between smoking and baldness. ${ }^{11}$ This relationship stretches from the microvasculature of the dermal hair papilla to a smoking induced imbalance in the follicular protease/antiprotease systems, which controls the tissue remodeling during the hair growth cycle. ${ }^{12}$

Received on 25-02-2021

Accepted on 29-05-2021
According to the data of the World Health Organization, ${ }^{13}$ Pakistan is among top 15 countries in tobacco consumption. In 2013, World Health Organization estimated the prevalence of smoking in the population of Pakistan: $31.8 \%$ of men, $5.8 \%$ of women, and $19.1 \%$ of Pakistan's adult population were habitual of smoking. Males were predominant in both urban and rural areas. ${ }^{14}$

Globally, researches have been conducted to show the significant relationship between smoking and baldness, however, there is a dearth of research based on primary data to unleash the relationship between baldness and smoking in the context of Pakistan. Therefore, a nuanced investigation was needed to identify the prevalence of baldness, and its association with stress and smoking, among the male population in Pakistan.

\section{SUBJECTS AND METHODS}

Study Design and Setting: A cross-sectional survey was designed. The data were collected by physically going into the field. Lahore, capital of Punjab, which is the second largest and diverse city of Pakistan, was selected as the unit of analysis for the current research

Sample Selection: Lahore, the capital of Punjab, Pakistan was selected as unit of analysis. Male of different ages were randomly selected. Using $7 \%$ margin of error, 0.52 male baldness frequency ${ }^{3}$ and $95 \%$ C.I. a sample size of 196 was calculated. However 250 participants were recruited in the study for maintaining result accuracy.

Study Tool: For the measurement of the prevalence and severity of baldness, the Norwood-Hamilton' Categorical scale $^{15}$ was used which consists of the grades or types of baldness, including "Type I, Type II, Type IIA, Type III, 
Type IIIA, Type III Vertex, Type IV, Type IVA, Type V, Type VA, Type VI and Type VII" (Figure 1).

Data Collection: After ensuring the confidentiality and anonymity of the respondents, visual mapping technique was used and respondents were asked to tick the most appropriate option (prevalence of baldness). The body mass index (BMI) of the participants was measured by using the standard calculator, weight in centimeters $(\mathrm{cm})$ and the weight in kilogram $(\mathrm{kg})$. The information pertaining to the status of smoking was collected by asking close ended questions in the survey. Moreover, the stress level was measured by using the Perceived Stress Scale (PSS). The PSS scores for low stress range from $0-18$, and the scores for moderate stress range from 19-36, while the scores for high stress range from $37-56 .^{16}$
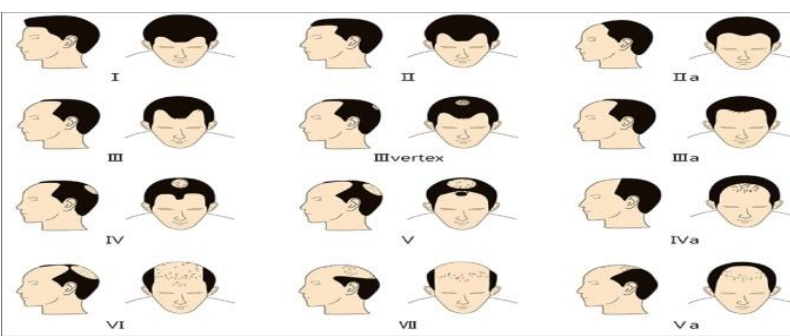

Figure 1: Norwood-Hamilton classification (adopted from Norwood OT. Male pattern baldness; classification and incidence. Southern Med J 1975;68 (11):1359-65)

Statistical Analysis: SPSS version 22.0 was used for the data analysis. For descriptive analysis, frequency, percentage and were applied. Inferential analysis was done to analyze the association between the variables. For this purpose, chi-square test was used to analyze the association between the variables with a significance of $P$ value $\leq 0.05$

\section{RESULTS}

A total of 250 participants was screened. Table 1 shows the socio-demographic profile of the study participants. Most of the study participants were married (78.4\%), living in a nuclear family arrangement $(67.6 \%)$ having normal BMI (32.8\%). Only 69 (27.6\%) of the study participants were smokers.

Additionally, the Frequency and percentage of the Stress Levels (Perceived Stress Scale) and the Norwood Hamilton Stage of the sampled males is shown in Table 2. The frequency of low, moderate and high stress levels was $7.6 \%, 51.2 \%$ and $41.2 \%$ respectively. According to the Norwood Hamilton stage individuals, who experienced a little baldness (less than the Type-III) constituted $35.6 \%$ of the individuals, Type III-V of baldness was present among $51.2 \%$ of the sampled population, and Type VI and VII were identified in $13.2 \%$ of these individuals. It is noteworthy that the most prevalent type of baldness was Type II, which is the fronto-temporal hairline recession, with $19.2 \%$ of the individuals experiencing it. Whereas, the least prevalent type of baldness among the bald people was Type IIA, in which the hairline is anterior to the coronal plane, at a $2 \mathrm{~cm}$ anterior to the external auditory meatus, and Type IV, in which the vertex is free of hair, or sparse hair is present, both types showing the same percentage of only $4.4 \%$.

The Chi-square association test was run in order to determine the relationship between the social-demographic variable, with the Norwood Hamilton category (Table 3). In this regard, the age and family type were the significant factors in determining the baldness in males. Type VI \& VII of baldness were more prevalent in this category, with $39.1 \%$ of the sampled population to be the men aged more than 50 years, followed by $33.1 \%$ of them being between the age of 31 to 50 years. Whereas, men whose age ranged between 18-30 years, constituted the highest percentage of the individuals $13.3 \%$. This difference was statistically significant $(p=<0.001)$, where the Types VI \& VII, with a total percentage of $34.3 \%$ of the sample population, were common among the males who were living in a nuclear family type, and Types VI \& VII were common among $13.6 \%$ of those men who were living in an extended family arrangement. On the contrary, the relationship between the educational status, body mass index, smoking status and the type of baldness in males was statistically insignificant, with the values $p=0.297$, $p=0.218, p=0.618$, respectively.

Table 1: Socio-demographic Profile

\begin{tabular}{|l|l|c|}
\hline \multicolumn{2}{|c|}{} & \multicolumn{1}{|c|}{$\begin{array}{c}\text { Frequency } \\
\mathbf{n}(\%)\end{array}$} \\
\hline \multirow{4}{*}{ Education } & Illiterate & $07(2.8 \%)$ \\
\cline { 2 - 3 } & Up till Matric & $106(42.2 \%)$ \\
\cline { 2 - 3 } & Intermediate & $57(22.8 \%)$ \\
\cline { 2 - 3 } & Graduation & $80(32.2 \%)$ \\
\hline \multirow{3}{*}{ Marital Status } & Single & $53(21.2 \%)$ \\
\cline { 2 - 3 } & Married & $196(78.4 \%)$ \\
\cline { 2 - 3 } Family Type & Divorced & $01(0.4 \%)$ \\
\hline \multirow{3}{*}{$\begin{array}{l}\text { Body Mass Index } \\
\text { (BMI) }\end{array}$} & Nuclear & $169(67.6 \%)$ \\
\cline { 2 - 3 } & Extended & $81(32.4 \%)$ \\
\cline { 2 - 3 } & Under Weight & $27(10.8 \%)$ \\
\cline { 2 - 3 } & Normal & $82(32.8 \%)$ \\
\cline { 2 - 3 } Smoking Status & Overweight & $70(28 \%)$ \\
\cline { 2 - 3 } & Oese & $71(28.4 \%)$ \\
\cline { 2 - 3 } & No & $69(27.6 \%)$ \\
\hline
\end{tabular}

Table 2: Stress Levels (Perceived Stress Scale) and Norwood Hamilton Stage of the Individuals

\begin{tabular}{|l|l|c|}
\hline \multicolumn{2}{|l|}{} & \multicolumn{1}{|c|}{$\begin{array}{c}\text { Frequency } \\
\mathbf{n}(\%)\end{array}$} \\
\hline $\begin{array}{l}\text { Stress Levels } \\
\text { (Perceived }\end{array}$ & Low Stress & $19(7.6 \%)$ \\
\cline { 2 - 3 } Stress Scale) & Moderate Stress & $128(51.2 \%)$ \\
\cline { 2 - 3 } & High Stress & $103(41.2 \%)$ \\
\hline \multirow{5}{*}{ Norwood Stage } & Type I & $30(12 \%)$ \\
\cline { 2 - 3 } & Type II & $48(19.2 \%)$ \\
\cline { 2 - 3 } & Type IIA & $11(4.4 \%)$ \\
\cline { 2 - 3 } & Type III & $29(11.6 \%)$ \\
\cline { 2 - 3 } & Type IIIA & $18(7.2 \%)$ \\
\cline { 2 - 3 } & Type III Vertex & $21(8.4 \%)$ \\
\cline { 2 - 3 } & Type IV & $11(4.4 \%)$ \\
\cline { 2 - 3 } & Type IVA & $13(5.2 \%)$ \\
\cline { 2 - 3 } & Type V & $20(8.0 \%)$ \\
\cline { 2 - 3 } & Type VA & $16(6.4 \%)$ \\
\cline { 2 - 3 } & Type VI & $14(5.6 \%)$ \\
\cline { 2 - 3 } & Type VII & $19(7.6 \%)$ \\
\hline
\end{tabular}

Similarly, in order to determine the association between the socio-demographic variables, and the stress 
levels, the chi-square was referred to (Table 4). The findings showed that the age factor and the body mass index were statistically insignificant with the $p$-values of 0.514 and 0.329 , respectively, whereas, the educational level, family type and smoking were found to be statistically significant, with a p-value of $0.011,0.006$ and 0.023 , respectively.

Table 3: Association of Socio-demographic Profile with Norwood Hamilton Stages

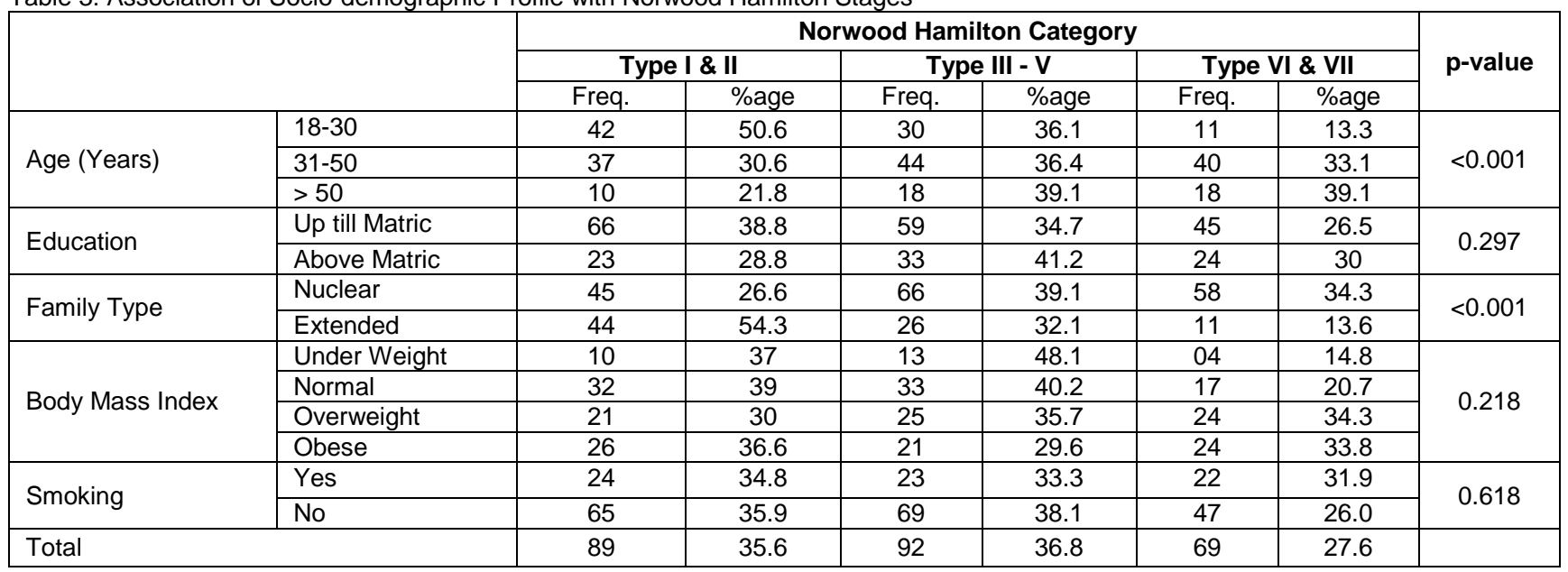

Table 4: Association of Socio-demographic Profile with Stress Levels

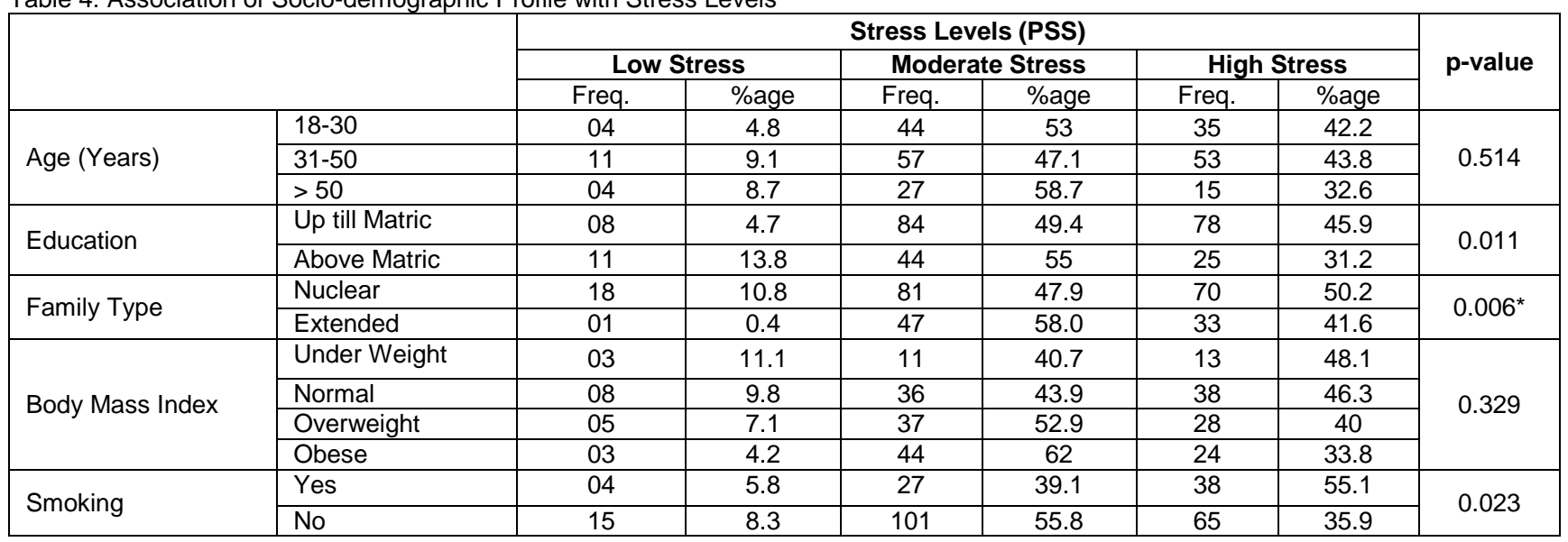

\section{DISCUSSION}

After empirical literature review, very limited studies came into our knowledge explaining the prevalence of hair loss with its types and its relationship to stress and tobacco use in male gender specifically in Pakistan Context. In this study age was statistically significant variable, according to the Norwood Hamilton scale, with a p-value $<0.001$. The findings of our study also advocated the findings of a previously conducted research in Australia that suggested that age is significantly associated with baldness. ${ }^{17}$ Also, on the Norwood Hamilton Scale, the family type appears to be significant with the $p$-value $<0.001$. A higher incidence of baldness was recorded in those men who lived in a nuclear family arrangement, which is also in consistent with the extant studies' findings. ${ }^{18,} 19$ Moving in the same stride, Soorihet $\mathrm{al}^{3}$ found an association between hair loss and stress. A perceived stress scale was used to determine the stress level among 236 males. The results were quite similar in a context that the majority of the male respondents were going through moderate levels of stress.

In this study, the percentage of obesity (33.8\%) was highest among the highest category of the Norwood grades i.e., Type VI and VII, followed by the overweight individuals (34.3\%). Moreover, the stress levels were observed to be higher among the underweight respondents (48.1\%), followed by the normal weight individuals. These specific findings in our study were statistically insignificant, contradicting the previous study findings of Yang et $\mathrm{al}^{20}$ who determined an association between the severity of the grade and BMI. They concluded that the risk of developing alopecia was higher among the obese males (OR=4.97). This difference might be justified because of huge sociocultural and diet preference differences between the study participants.

This study was the first of its kind to be conducted in Lahore and based on the various stages of baldness and their association with smoking and stress. This study will be helpful for stakeholders to develop a constructive problem 
solving technique that will help to create awareness among the male members for the wellbeing of society.

\section{CONCLUSION}

Only $50(20 \%)$ males were found smoker. Study concluded that there is no association between the levels of stress, smoking and the various stages of baldness.

\section{REFERENCES}

1. Shrivastava SB. Diffuse hair loss in an adult female: approach to diagnosis and management. Indian Journal of Dermatology, Venereology, and Leprology. 2009;75(1):20.

2. Zhang X, Caulloo S, Zhao Y, Zhang B, Cai Z, Yang J. Female pattern hair loss: clinico-laboratory findings and trichoscopy depending on disease severity. International journal of trichology. 2012;4(1):23.

3. Shaikh S, Shaikh S, Shaikh S, Shaikh AA, Saleem SG. PREVALENCE OF HAIR LOSS AND STRESS AS THE CAUSE; A CROSS-SECTIONAL STUDY.

4. Alves R. Androgenetic Alopecia: a Review and Emerging Treatments. Clin Res Dermatol Open Access. 2017;4(4):1-13.

5. Zayed AA, Shahait AD, Ayoub MN, Yousef A-M. Smokers' hair: Does smoking cause premature hair graying? Indian dermatology online journal. 2013;4(2):90.

6. Kranz D. Young men's coping with androgenetic alopecia: Acceptance counts when hair gets thinner. Body Image. 2011;8(4):343-8.

7. Liu N, Wang L-H, Guo L-L, Wang G-Q, Zhou X-P, Jiang $Y$, et al. Chronic restraint stress inhibits hair growth via substance $P$ mediated by reactive oxygen species in mice. PloS one. 2013;8(4):e61574.

8. Peters EM, Müller $Y$, Snaga $W$, Fliege $H$, Reißhauer A, Schmidt-Rose T, et al. Hair and stress: A pilot study of hair and cytokine balance alteration in healthy young women under major exam stress. Plos one. 2017;12(4):e0175904.

9. Aggarwal A, Srivastava S, Agarwal M, Dwivedi S. Premature graying of hair: An independent risk marker for coronary artery disease in smokers-A retrospective case control study. Ethiopian journal of health sciences. 2015;25(2):123-8

10. Davis EM, Peck JD, Peck BM, Kaplan HB Associations between early alcohol and tobacco use and prolonged time to puberty in boys. Child: care, health and development. 2015;41(3):459-66.

11. Su L-H, Chen TH-H. Association of androgenetic alopecia with smoking and its prevalence among Asian men: a community-based survey. Archives of dermatology. 2007;143(11):1401-6.

12. Trüeb RM. Association between smoking and hair loss: another opportunity for health education against smoking? Dermatology. 2003;206(3):189-91.

13. Khan JA, Amir Humza Sohail AM, Arif Maan MA. Tobacco control laws in Pakistan and their implementation: A pilot study in Karachi. Journal of Pakistan Medical Association. 2016;66(7):875.

14. Alan S. Prevalence and pattern of smoking in Pakistan. JOURNAL-PAKISTAN MEDICAL ASSOCIATION. 1998:48:64-5.

15. Norwood OT. Male pattern baldness: classification and incidence. Southern medical journal. 1975;68(11):1359-65.

16. Cohen S, Kamarck T, Mermelstein R. Perceived stress scale. Measuring stress: A guide for health and social scientists. 1994;10:1-2.

17. Sinclair R. Prevalence of male and female pattern hair loss in Maryborough. 2005.

18. Gul S, Khan T, Naz S, Malick A, Kaleem S. Hair fall, Its Effective Available Treatments and Toxic Chemicals Associated with It. RADS Journal of Pharmacy and Pharmaceutical Sciences. 2013;1(1):11-5.

19. VARMAN P, PAUL C, Rajan P, Preethi R, PRIYA R, PRIYANKA S. Study on Hair Fall with Hair Related Problems among Males of Age 18-50 Years: Study on Chennai Based Population. Journal of Clinical \& Diagnostic Research. 2018;12(10).

20. Yang C-C, Hsieh F-N, Lin L-Y, Hsu C-K, Sheu H-M, Chen W. Higher body mass index is associated with greater severity of alopecia in men with male-pattern androgenetic alopecia in Taiwan: a cross-sectional study. Journal of the American Academy of Dermatology. 2014;70(2):297-302. e1. 